Appendix I

\title{
The Mathematics Practical Worksheet
}




\section{Problem}

Print the problem here.

\section{Instructions}

1. You may proceed to complete the worksheet doing stages I - IV.

2. If you wish, you have 15 minutes to solve the problem without explicitly using Polya's model. Do your work in the space for Stage III.

If you are stuck after 15 minutes, use Polya's model and complete all the stages I-IV.

If you can solve the problem, you must proceed to do stage IV Check and Expand.

I Understand the problem

(You may have to return to this section a few times. Number each attempt to understand the problem accordingly as Attempt 1, Attempt 2, etc.)

(a) Write down your feelings about the problem. Does it bore you? scare you? challenge you?

(b) Write down the parts you do not understand now or that you misunderstood in your previous attempt.

(c) Write down your attempt to understand the problem; and state the heuristics you used.

\section{Attempt 1}




\section{Devise a plan}

(You may have to return to this section a few times. Number each new plan accordingly as Plan 1, Plan 2, etc.)

(a) Write down the key concepts that might be involved in solving the problem.

(b) Do you think you have the required resources to implement the plan?

(c) Write out each plan concisely and clearly.

$\underline{\text { Plan } 1}$ 


\section{Carry out the plan}

(You may have to return to this section a few times. Number each implementation accordingly as Plan 1, Plan 2, etc., or even Plan 1.1, Plan 1.2, etc. if there are two or more attempts using Plan 1.)

(i) Write down in the Control column, the key points where you make a decision or observation, for eg., go back to check, try something else, look for resources, or totally abandon the plan.

(ii) Write out each implementation in detail under the Detailed Mathematical Steps column.

Detailed Mathematical Steps

Control

Attempt 1 


\section{Check and Expand}

(a) Write down how you checked your solution.

(b) Write down your level of satisfaction with your solution. Write down a sketch of any alternative solution(s) that you can think of.

(c) Give one or two adaptations, extensions or generalisations of the problem. Explain succinctly whether your solution structure will work on them. 
This page is intentionally left blank 
Appendix II

Sample of Student's Work 


\section{Practical Worksheet}

\section{Problem}

\section{The Lockers Problem}

The new school has exactly 343 lockers numbered 1 to 343 , and exactly 343 students. On the first day of school, the students meet outside the building and agree on the following plan. The first student will enter the school and open all the lockers. The second student will then cnter the school and close every locker with an even number. The third student will then 'reverse' every third locker; i.c. if the locker is closed, he will open it, and if the locker is open, he will close it. The fourth student will reverse every fourth locker, and so on until all 343 students in turn have entered the building and reversed the relevant lockers. Which lockers will finally remain open?

\section{Instructions}

- You may proceed to complete the worksheet doing stages I-IV.

- If you wish, you have 15 minutes to solve the problem without explicitly using Polya's model. Do your work in the space for Stage III.

v If you are stuck after 15 minutes, use Polya's model and comptete all the stages I - IV.

v If you can solve the problem, you must proceed to do stage IV - Check and Extend.

\section{Understand the problem}

(You may have to return to this section a few times. Number each attempt to understand the problem accordingly as Attempt 1, Attempt 2, etc.)

(a) Write down your feelings about the problem. Does it bore you? scare you? challenge you?

(b) Write down the parts you do not understand now or that you misunderstood in your previous attempt.

(c) Write down your attempt to understand the problem; and state the heuristics you used.

\section{Attempt 1}

(a) The question has sparked my interest die to the unusual nature of the problem. I believe that this prodem would prove to be challenging, and conventional methods taught in school may not be sufficient to tarke this problem.

(b) $N / A$

(c) Simulation of 10 lockers, 10 students.

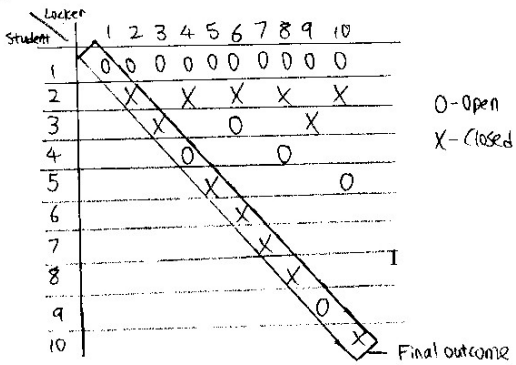

Open lockers: $1,4,9$

closed lockers: $2,3,5,6,7,8,10$ 
II Devise a plan

(You may have to return to this section a few times. Number each new plan accordingly as Plan 1, Plan 2, etc.)

(a) Write down the key concepts that might be involved in solving the problem.

(b) Do you think you have the required resources to implement the plan?

(c) Write out each plan concisely and clearly.

\section{Plan 1}

(a) Finding number of factors a number has

(b) Yes

1. Consider any integer $n$, where $1 \leqslant n \leqslant 343$.

2. Label the students from 1 to 343 , according to the lockers they reverse

3. observe which students open locker $n$

4. Deduce a relation from $n$, and prove if possible

5. Identify conditions for $n$ to be open/closed.

6. If successful, find all open lockers. 


\section{Carry out the plan}

(You may have to return to this section a few times. Number each implementation accordingly as Plan 1, Plan 2, etc., or even Plan 1.1, Plan 1.2, etc. if there are two or more atternpts using Plan 1. )

(i) Write down in the Control column, the key points where you make a decision or observation, for e.g., go back to check, try something else, look for resources, or totally abandon the plan.

(ii) Write out each implementation in detail under the Detailed Mathematical Steps column.

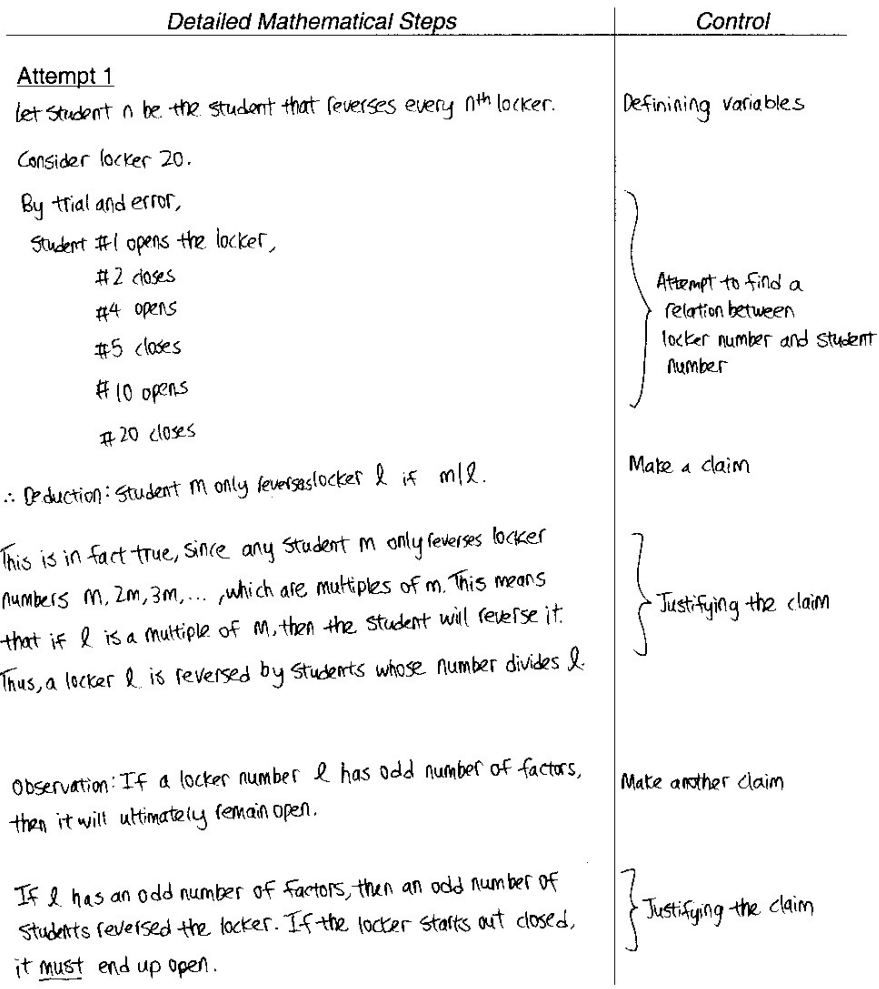


It remains to find locker numbers which have an odd number of factors.

prime

suppose the locker number $l$ has the follawing factorisation:

$$
l=p_{1}^{q_{1}} p_{2}^{q_{2}} \ldots p_{4}^{q_{4}}
$$

Then it has the following factor:

$p_{1}^{r_{1}} p_{2}^{r_{2}} \cdots p_{y}^{r_{y}} \mid p_{1}^{q_{1}} p_{2}^{q_{2}} \ldots p_{y}^{q_{y}}, 0 \leqslant r_{i} \leqslant q_{i}, 1 \leqslant i \leqslant y$

$r_{i}$ can take. $q_{i}+1$ values, and by simple combinatorics, the total number of factors $l$ can have is given by

$$
\prod_{i=1}^{y}\left(q_{i}+1\right)=\text { number of factors of } l \text {. }
$$

Since we want number of factors to be odd, there must be no even number in the muttiplication. That is,

$$
\left(q_{1}+1\right),\left(q_{2}+1\right), \ldots,\left(q_{y}+1\right) \text { ale all odd numbers. }
$$

Equivalentily,

$q_{1}, q_{2}, q_{3}, \ldots, q_{y}$ are all even numbers.

This means that $q_{1}, q_{2}, \ldots, q_{y}$ will yield an integer if dividad by 2 . Also, this relates to $\sqrt{l}$ having an integer value $\Rightarrow l$ is a squale number.

conclusion: All lockerswhose number is a perfect square winl be open.

If a locker whose number $l^{\prime}$ is not a square number, then there. must exist in the prime factorisation a $p_{x}^{q_{x}}$ where $q_{x}$ is odd. This mans that $(q x+1)$ is even. Hus $l^{\prime}$ has an even number of factors by (*). This relates to an even number of students reversing the locker, which means if it starts ant closed, it wit uttimately beclosed.

$\therefore$ Lockers that remain open ale numbers under 343 and ale perfect squales. Namely: $1,4,9,16,25,36,49,54,81,100$,

$121,144,169,196,225,256,289,324$

Ootaining the neressary condition for locker \& to remain open
Shawing that the

condition is sufficient 


\section{Check and Expand}
(a) Write down how you checked your solution.
(b) Write down your level of satisfaction with your solution. Write down a sketch of any alternative solution(s) that you can think of.
(c) Give one or two adaptations, extensions or generalisations of the problem. Explain succinctly whether your solution structure will work on them.

(a) From the simple 10-student/locker simulation, the result is correct. Square numbers ale chected to be the only integers that have an odd number of factors, and are thus the only lockers that are open.

(b) Satisfied.

\section{Atemative solution}

It is noted that if student $m$ opens locker $l$, then student $\frac{l}{m}$ opens locker $l$ as well.

This is generally true, since both $m$ and $\frac{l}{m}$ are integers less than $l$, and both are factors of $\ell$.

Thus, if $a_{1}, a_{2}, a_{3}, \ldots, a_{n}$ are factors of $l$ less than $l l$,

$a_{1}$ opens $\rightarrow \frac{l}{a_{1}}$ closes

$a_{2}$ opens $\rightarrow \frac{1}{a_{2}}$ clases

$$
a_{n} \text { opens } \rightarrow \frac{\ell}{a_{n}} \text { closes }
$$

Here dees not exist any $a_{i}$ which has the same as any $\frac{l}{a_{j}}$, since all $a_{i} \leq \sqrt{n}$, and $a_{j} \geq \sqrt{n}$ unkss $a_{i}=\frac{l}{a_{i}}=\sqrt{l}$. In that case $a_{i}$ will open, and no $\frac{l}{a_{i}}$ will close, ultimately resulting in the locker being open. For such $a_{i}$ to exist, $\sqrt{l}$ must be an intoger.

$\therefore l$ must be a perfect square.

Ans: $1,49,16,25,36,49,64,81,100,121,144,169,196,225,256,289,324$ 
This page is intentionally left blank 
Appendix III

\section{Rubrics for Assessment}


Name:

\begin{tabular}{|c|c|c|}
\hline \multicolumn{3}{|c|}{ Polya's Stages } \\
\hline & $\begin{array}{l}\text { Descriptors/Criteria (evidence suggested/indicated } \\
\text { on practical sheet or observed by teacher) }\end{array}$ & $\begin{array}{l}\text { Marks } \\
\text { Awarded }\end{array}$ \\
\hline \multicolumn{3}{|c|}{ Correct Solution } \\
\hline Level 3 & $\begin{array}{l}\text { Evidence of complete use of Pólya's stages - UP } \\
+\mathrm{DP}+\mathrm{CP} \text {; and when necessary, appropriate } \\
\text { loops. }[10 \text { marks] }\end{array}$ & \\
\hline Level 2 & $\begin{array}{l}\text { Evidence of trying to understand the problem } \\
\text { and having a clear plan }-\mathrm{UP}+\mathrm{DP}+\mathrm{CP} \text {. } \\
{[9 \text { marks }]}\end{array}$ & \\
\hline Level 1 & $\begin{array}{l}\text { No evidence of attempt to use Pólya's stages. } \\
\text { [8 marks] }\end{array}$ & \\
\hline \multicolumn{3}{|c|}{$\begin{array}{l}\text { Partially Correct Solution (solve significant part of the problem or lacking } \\
\text { rigour) }\end{array}$} \\
\hline Level 3 & $\begin{array}{l}\text { Evidence of complete use of Pólya's stages - UP } \\
+\mathrm{DP}+\mathrm{CP} \text {; and when necessary, appropriate } \\
\text { loops. }[8 \text { marks] }\end{array}$ & \\
\hline Level 2 & $\begin{array}{l}\text { Evidence of trying to understand the problem } \\
\text { and having a clear plan }-\mathrm{UP}+\mathrm{DP}+\mathrm{CP} \text {. } \\
{[7 \text { marks }]}\end{array}$ & \\
\hline Level 1 & $\begin{array}{l}\text { No evidence of attempt to use Pólya's stages. } \\
\text { [6 marks] }\end{array}$ & \\
\hline
\end{tabular}




\begin{tabular}{|l|l|l|}
\hline \multicolumn{2}{|l|}{ Incorrect Solution } \\
\hline Level 3 & $\begin{array}{l}\text { Evidence of complete use of Polya's stages - UP } \\
+\mathrm{DP}+\mathrm{CP} \text { and when necessary, appropriate } \\
\text { loops. [6 marks] }\end{array}$ & \\
\hline Level 2 & $\begin{array}{l}\text { Evidence of trying to understand the problem } \\
\text { and having a clear plan }-\mathrm{UP}+\mathrm{DP}+\mathrm{CP} . \\
{[5 \text { marks }]}\end{array}$ & \\
\hline Level 1 & $\begin{array}{l}\text { No evidence of attempt to use Pólya's stages. } \\
{[0 \text { marks] }}\end{array}$ & \\
\hline
\end{tabular}

\begin{tabular}{|l|l|l|}
\hline Heurisitcs & $\begin{array}{l}\text { Descriptors/Criteria (evidence } \\
\text { suggested/indicated on practical sheet or } \\
\text { observed by teacher) }\end{array}$ & $\begin{array}{l}\text { Marks } \\
\text { Awarded }\end{array}$ \\
\hline Correct Solution & $\begin{array}{l}\text { Evidence of appropriate use of heuristics. } \\
\text { [4 marks] }\end{array}$ & \\
\hline Level 2 & No evidence of heuristics used. [3 marks] & \\
\hline Level 1 & $\begin{array}{l}\text { Evidially } \text { Correct Solution (solve significant part of the problem or lacking } \\
\text { rigour) }\end{array}$ & \\
\hline Level 2 2 marks] \\
\hline Level 1 & No evidence of heuristics used. [2 marks] & \\
\hline Incorrect Solution & $\begin{array}{l}\text { Evidence of appropriate use of heuristics. } \\
{[2 \text { marks] }}\end{array}$ & \\
\hline Level 2 & \\
\hline
\end{tabular}




\begin{tabular}{|c|c|c|}
\hline Level 1 & No evidence of heuristics used. [0 marks] & \\
\hline \multicolumn{3}{|c|}{ Checking and Expanding } \\
\hline & $\begin{array}{l}\text { Descriptors/Criteria (evidence } \\
\text { suggested/indicated on practical sheet or } \\
\text { observed by teacher) }\end{array}$ & $\begin{array}{l}\text { Marks } \\
\text { Awarded }\end{array}$ \\
\hline \multicolumn{3}{|l|}{ Checking } \\
\hline Level 2 & $\begin{array}{l}\text { Checking done }- \text { mistakes identified and } \\
\text { correction attempted by cycling back to UP, DP, } \\
\text { or } \mathrm{CP} \text {, until solution is reached. [ } 1 \text { mark] }\end{array}$ & \\
\hline Level 1 & $\begin{array}{l}\text { No checking, or solution contains errors. } \\
{[0 \text { marks }]}\end{array}$ & \\
\hline \multicolumn{3}{|c|}{ Alternative Solutions } \\
\hline Level 3 & $\begin{array}{l}\text { Two or more correct alternative solutions. } \\
{[2 \text { marks] }}\end{array}$ & \\
\hline Level 2 & One correct alternative solution. [1 mark] & \\
\hline Level 1 & No alternative solution. [0 marks] & \\
\hline \multicolumn{3}{|c|}{ Extending, Adapting \& Generalizing } \\
\hline Level 4 & $\begin{array}{l}\text { More than one related problem with suggestions } \\
\text { of correct solution methods/strategies; or } \\
\text { one significant related problem, with suggestion } \\
\text { of correct solution method/strategy; or } \\
\text { one significant related problem, with } \\
\text { explanation why method of solution for original } \\
\text { problem cannot be used. [ } 3 \text { marks] }\end{array}$ & \\
\hline Level 3 & $\begin{array}{l}\text { One related problem with suggestion of correct } \\
\text { solution method/strategy. [2 marks] }\end{array}$ & \\
\hline
\end{tabular}




\begin{tabular}{|l|l|l|}
\hline Level 2 & $\begin{array}{l}\text { One related problem given but without } \\
\text { suggestion of correct solution method/strategy. } \\
{[1 \text { mark }]}\end{array}$ & \\
\hline Level 1 & None provided [0 marks] & \\
\hline
\end{tabular}

Hints given:

Marks deducted:

Total marks: 